\title{
Salim Bachi, La Kahéna
}

\section{Giuliva Milò}

\section{(2) OpenEdition}

\section{Journals}

\section{Édition électronique}

URL : https://journals.openedition.org/studifrancesi/38471

DOI : 10.4000/studifrancesi.38471

ISSN : 2427-5856

\section{Éditeur}

Rosenberg \& Sellier

\section{Édition imprimée}

Date de publication : 15 décembre 2004

Pagination : 662-663

ISSN : 0039-2944

\section{Référence électronique}

Giuliva Milò, «Salim Bachi, La Kahéna », Studi Francesi [En ligne], 144 (XLVIII | III) | 2004, mis en ligne le 30 novembre 2015, consulté le 08 mai 2021. URL : http://journals.openedition.org/studifrancesi/ 38471 ; DOI : https://doi.org/10.4000/studifrancesi.38471

\section{Ce document a été généré automatiquement le 8 mai 2021.}

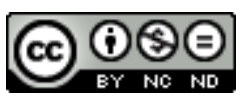

Studi Francesi è distribuita con Licenza Creative Commons Attribuzione - Non commerciale - Non opere derivate 4.0 Internazionale. 


\title{
Salim Bachi, La Kahéna
}

\author{
Giuliva Milò
}

\section{RÉFÉRENCE}

SALIM BACHI, La Kahéna, Paris, Gallimard, 2003, pp. 309.

1 Après une entrée fulgurante dans le monde des lettres avec Le chien d'Ulysse (Gallimard, 2001) qui lui a valu le "prix de la vocation", Salim Bachi, jeune écrivain de 30 ans, publie déjà son deuxième roman dont le titre autrement suggestif, La Kahéna, du nom de

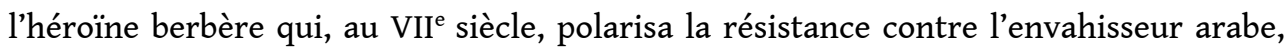
laisse planer comme un mystère autour de l'histoire des origines. Dans le livre, $L a$ Kahéna est le nom de la maison que le colon maltais Louis Bergagna se fit construire au début du $\mathrm{XX}^{\mathrm{e}}$ siècle quand, de retour de ses voyages aventureux en Guyane et en Amazonie brésilienne, il décida de s'installer définitivement en Afrique du Nord, et plus précisément à Cyrtha où il devint maire. Par respect des convenances coloniales il épousa Sophie, une danseuse ramenée de Paris qui jamais ne s'acclimata ou pays, mais aima sincèrement, bien qu'en secret, une femme arabe à son service. Au moment de la décolonisation, il fut tué dans le jardin de cette maison qui, pour lui, était devenue une véritable citadelle. Mais Cyrtha, est-ce bien l'ancienne ville de Constantine ou le pur produit des divagations du héros, Hamid Kaïm, qui, sous l'effet de l'alcool, en trois nuits, comme dans un conte, révèle peu à peu à la narratrice, son actuelle maîtresse, le secret de ses origines? Quel est donc le lien qui unit Hamid Kaïm et Louis Bergagna? Apparemment aucun sinon cette maison que le père de Hamid Kaïm avait rachetée après 1962 et où maintenant notre héros, sur les traces du passé, est revenu en compagnie de la narratrice qui, à plusieurs reprises, avoue être tentée d'abandonner l'écoute interminable d'un récit dont le fil conducteur n'est pas toujours bien visible. Mais c'est là une stratégie d'écriture fonctionnelle à l'élan proleptique du roman qui, au contraire, tient en haleine le lecteur, intrigué par le mystère qui subsiste autour de l'histoire d'un amour impossible entre le héros et la belle Samira et par une quête 
identitaire où les légendes mythiques s'entremêlent aux événements les plus saillants de l'histoire collective, de la colonisation à nos jours.

2 Ainsi l'originalité du roman tient à sa structure labyrinthique, comme l'architecture même de la Kahéna, où la recherche du passé se fait à travers différents récits emboîtés les uns dans les autres et consignés par le héros à la narration, toute aussi originale, de sa compagne-destinataire qui, à son tour, alimente la curiosité du lecteur appelé à contribuer à la constitution de l'histoire. Car la maison - citadelle recèle bien une énigme dont l'explication est à chercher dans les carnets de Louis Bergagna, enfouis dans un vieil hibou empaillé, et dans le manuscrit des mémoires du père de Hamid Kaïm. L'énigme ne sera cependant levée qu'en partie, "Hamid Kaïm ignorerait jusqu'à sa mort son identité véritable." Il retiendra, du moins, que la vérité, fuyante, ne cesse de se masquer et que s'il ignorait qui il était, où il allait, il ne désespérerait plus de ne jamais le savoir. À quoi pouvait alors rimer toute cette quête? Sans doute à "léguer l'amour des histoires" comme l'auteur fait dire à son héros lui-même qui, dans la tradition des Mille et une nuit, a réussi à captiver l'attention de sa maîtresse, et, de surcroît, des lecteurs, en créant une atmosphère énigmatique et féerique. Car la légende, dans sa vacuité, est plus vraie que la réalité dans la mesure où les hommes sont beaucoup plus prêts à s'attacher aux chimères du rêve et à se laisser entraîner par les divagations de la fantaisie. Voilà à quoi tient sans doute l'originalité et le succès de ce roman qui, en prenant finalement les distances par rapport à l'Histoire pour la mettre au service de la fantaisie, semble marquer comme un tournant dans la création littéraire de la nouvelle génération d'écrivains algériens. 